\title{
Assessment of effectiveness of anakinra and canakinumab in patients with colchicine-resistant/unresponsive familial Mediterranean fever
}

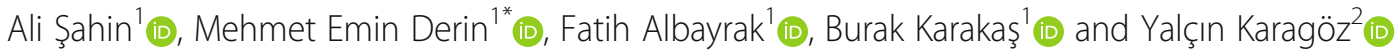

\begin{abstract}
İntroduction: Familial Mediterranean fever (FMF) is a hereditary auto-inflammatory disease characterized by recurrent fever and serosal inflammation. Anti-interleukin-1 (Anti-IL-1) treatments are recommended in colchicine resistant and/or intolerant FMF patients. This study aims to evaluate the efficacy of anakinra and canakinumab in FMF patients that are resistant/intolareted to colchicine or complicated with amyloidosis.

Methods: Between January 2014 and March 2019, 65 patients following-up at Sivas Cumhuriyet University (Medical Faculty Rheumatology-Internal Medicine Department) who were diagnosed with FMF according to the criteria of Tel-Hashomer were included in the study. The laboratory values and clinical features of patients and disease activities were recorded at least every 3 months, and these data were analyzed.

Results: Forty-one (63.1\%) patients used anakinra (100 mg/day) and 24 (36.9\%) patients used canakinumab (150 $\mathrm{mg} / 8$ week). The median duration of anti-IL-1 agents use was 7 months (range, 3-30). Fifteen (23.1\%) cases were complicated with amyloidosis. Seven (10.8\%) patients had renal transplantation. Overall, the FMF 50 score response was $96.9 \%$. In the group that had a glomerular filtration rate (GFR) $\geq 60 \mathrm{ml} / \mathrm{min} / \mathrm{m}^{2}$, the median proteinuria decreased from $2390 \mathrm{mg} /$ day (range, 1400-7200) to $890 \mathrm{mg} /$ day (range, 120-2750) ( $p=0.008$ ). No serious infections were detected, except in one patient.

Conclusions: Anti-IL-1 agents are effective and safe in the treatment of FMF patients. These agents are particularly effective at reducing proteinuria in patients with GFR $\geq 60 \mathrm{ml} / \mathrm{min} / \mathrm{m}^{2}$, but less effective in cases with FMF associated with arthritis and sacroiliitis. Large and long follow-up studies are now needed to establish the longterm effects of these treatments.
\end{abstract}

Keywords: Anakinra, Canakinumab, Familial Mediterranean fever (FMF), Amyloidosis, Colchicine-resistant

\section{Introduction}

Familial Mediterranean fever (FMF) is a monogenic autoinflammatory disease characterized by self-limiting acute inflammatory attacks involving the peritoneum, synovium, pleura, and (rarely) pericardium, often accompanied by fever [1]. Turkey has the highest prevalence of FMF in any country in the world. The prevalence of FMF in Turkey shows regional characteristics. The

\footnotetext{
* Correspondence: eminderin@gmail.com

${ }^{1}$ Department of Internal Medicine - Rheumatology, Faculty of Medicine,

Cumhuriyet University, Unit Sivas Cumhuriyet, 58140 Sivas, Turkey

Full list of author information is available at the end of the article
}

prevalence rate is $0.25-0.88 \%$ in the Central Anatolia region, such as Sivas, Tokat, Erzincan, and Kastamonu $[2,3]$. A Turkish FMF study group has reported that 90\% of FMF patients in Turkey originate from the East and Black Sea and Central Anatolia regions [4]. The most severe complication of FMF is type AA amyloidosis. Nephrotic syndrome and end-stage renal failure tend to occur within 5-10 years in untreated FMFassociated amyloidosis patients [5]. The basic treatment goal for FMF is to prevent the attacks and to minimize the subclinical inflammation between attacks. Specifically, the main treatment for amyloidosis and FMF 
attacks is colchicine. Colchicine resistance in FMF patients is about $5-15 \%$ [6]. Patients who use maximum dose colchicine treatment $(3 \mathrm{mg} /$ day $)$ for at least 6 months are considered resistant/unresponsive to colchicine if they had one or more attacks per month. Biological agents, such as anti-interleukin-1 (IL) agents, are indicated in these patients [7]. In Turkey, anakinra (recombinant IL-1 antagonist, kineret ${ }^{\circ}, 100 \mathrm{mg} /$ day/subcutaneous) and canakinumab (IL-1 $\beta$ antibody, ilaris ${ }^{\circ} 150$ $\mathrm{mg} / 8$ weeks/subcutaneous) are used as anti-IL-1 treatments. Rinolocept, which is another anti-IL-1 agent, is not available in Turkey. Treatments in Turkey can be used by obtaining an off-label consent from the Turkey Medicines and Medical Devices Institution (TICTK). The purpose of this study is to share our clinical evaluation of anti-IL-1 treatment for FMF patients who have colchicine resistance or intolerance.

\section{Materials and methods}

Between January 2014 and March 2019, 65 patients who were admitted to Sivas Cumhuriyet University Hospital Internal Medicine Rheumatology Department were included in the study.

Our department includes a total of about $800-1000$ FMF patients. The enrolled patients, who were diagnosed with FMF according to the Tel-Hashomer Criteria, had colchicine resistance/intolerance and were being treated with anti-IL-1 (anakinra or canakinumab) treatment. The European League Against Rheumatism (EULAR) criteria and recommendations were used to define colchicine resistance [7]. Patients who received the maximally tolerated dose colchicine treatment (3 $\mathrm{mg} /$ day) for at least 6 months were considered resistant/ unresponsive to colchicine if they had one or more attacks per month. Intolerance to colchicine or proteinuria were other indications of anti-IL-1 therapy. The factors for deciding whether to start anakinra or canakinumab treatments varied from patient to patient.

Data had been collected when the patients were called for their routine check-ups once every 3 months. For each visit, we recorded whether they had an FMF attack. Moreover, patients' global and physicians' global assessments of disease severity [on a visual analog scale (VAS), range 0 to 10], acute phase reactants, erythrocyte sedimentation rate (ESR), $C$ reactive protein (CRP), complete blood count ( $\mathrm{CBC})$, liver and kidney function values, and 24-h urinary protein levels were retrospectively investigated and included in our data. Patients who used anti-IL-1 treatment for at least 3 months were included in the study. Patients who were followed up for at least 3 months but discontinued treatment or followup for any reason were also included in the study. The FMF-50 score was used for the evaluation of responses. When at least five of the six variables were reduced by more than 50\%, the patient was considered to be responding to treatment.

Approval from the ethics committee of Cumhuriyet University Medical Faculty was obtained (decision no 2019-04/29). The study was carried out in accordance with the World Medical Association's Declaration of Helsinki. Patients' informed consents were obtained.

\section{Statistical analysis}

The SPSS 23.0 statistical program was used for the analysis of our data. The normality of the data was checked using the Kolmogorov-Smirnov statistical test. The independent sample t-test was used for the independent groups, which satisfy the parametric conditions. More than two groups were analyzed by the F test (ANOVA). If satisfied the homogeneity assumption, the Tukey test was used to analyze which groups were different from the others, whereas Tamhane's T2 test was used for the groups that did not satisfy the homogeneity assumption. If one or all of the assumptions were not met, the Mann Whitney $\mathrm{U}$ test was used for two independent groups, the Wilcoxon test for two conjugate groups, and the Kruskal Wallis test for more than two independent groups. For the significance test, a $p$-value smaller than 0.05 was used.

\section{Results}

\section{Demographic and clinical characteristics}

In total, 65 patients were involved in this study. The median age of the patients was 32 years (range, 17-60 years). Thirty-three $(50.8 \%)$ patients were male, and 30 (49.2\%) were female. Forty-one (63.1\%) patients used anakinra (100 mg/day/subcutaneous) and 24 (36.9\%) patients used canakinumab ( $150 \mathrm{mg} / 8$ week subcutaneous). The median duration of drug use was 6 months (range, 3-30 months) for anakinra and 8 months (range, 3-25 months) for canakinumab. The demographic and clinical features of the patients are shown in Table 1. Fifty-six of $65(86.7 \%)$ patients continued to be followed up. Twelve of the patients directly started with canakinumab (50\%), eight patients continued with canakinumab due to an allergic reaction to anakinra, and four patients used canakinumab because of inadequate response to anakinra (possibly due to non-compliance with treatment). Except for eight patients who had colchicine intolerance, 57 (87.7\%) patients continued to used colchicine (mean, 2 $\mathrm{mg} /$ day; range, $0.5-2.5 \mathrm{mg} /$ day). The Mediterranean fever gene $(M E F V)$ mutation analysis is shown in Table 1. The homozygous $M 694 \mathrm{~V}$ mutation was the most frequent mutation, detected in $29(44.6 \%)$ of the patients.

\section{Treatment response}

Before the treatment, the median FMF attack frequency over 3 months was three (range, 1-6), but was zero after 
Table 1 Demographic and clinical features

\begin{tabular}{|c|c|c|}
\hline \multicolumn{2}{|l|}{ Age } & 32 years $(17-60)$ \\
\hline \multicolumn{2}{|l|}{ Age of onset } & 18 years $(3-46)$ \\
\hline \multicolumn{3}{|l|}{ Sex } \\
\hline Female & n: 32 & $49.2 \%$ \\
\hline Male & n: 33 & $50.8 \%$ \\
\hline Duration of use & n: 65 (100\%) & 7 month (3-30) \\
\hline Anakinra & n: 41 (63.1\%) & 6 month $(3-30)$ \\
\hline Canakinumab & n: 24 (39.6\%) & 8 month (3-25) \\
\hline \multicolumn{3}{|l|}{ Clinical Features } \\
\hline Fever & n: 60 & $92.5 \%$ \\
\hline Peritonitis & $\mathrm{n}: 61$ & $93.8 \%$ \\
\hline Erysipales LE & n: 18 & $27.7 \%$ \\
\hline Amlyloidosis & n: 15 & $23.1 \%$ \\
\hline Arthritis & $\mathrm{n}: 11$ & $16.9 \%$ \\
\hline Pleuritis & $\mathrm{n}: 20$ & $30.8 \%$ \\
\hline AxSpa & n: 9 & $13.8 \%$ \\
\hline Renal trans & $\mathrm{n}: 7$ & $10.8 \%$ \\
\hline \multicolumn{3}{|l|}{ MEFV Mutation } \\
\hline M694 V homozygous & n: 29 & $44.6 \%$ \\
\hline M694 V heterozygous & n: 8 & $12.3 \%$ \\
\hline M680l homozygous & n: 4 & $6.2 \%$ \\
\hline E148Q homozygous & $\mathrm{n}: 1$ & $1.5 \%$ \\
\hline Compound & n: 16 & $24.6 \%$ \\
\hline No & n: 3 & $4.6 \%$ \\
\hline $\mathrm{R} 761 \mathrm{H}$ heterozygous & $\mathrm{n}: 1$ & $1.5 \%$ \\
\hline Others & $\mathrm{n}: 3$ & $4.6 \%$ \\
\hline \multicolumn{3}{|c|}{ Indications of Anti-IL1 therapy } \\
\hline Colchicine-Intolerant & $\mathrm{n}: 8$ & $12.3 \%$ \\
\hline Colchicine-Resistant & n: 46 & $70.8 \%$ \\
\hline Proteinuria & $\mathrm{n}: 15$ & $23.1 \%$ \\
\hline
\end{tabular}

All parameters are presented as median (min-max) or number (\%). LE like erythema, AxSpa axialspondyloarthropathy

treatment (range, $0-1)(p=0.00)$. There was a statistically significant improvement in the physician's VAS, ESR, CRP, and attack duration with anti-IL-1 treatment (Table 2). We found that 63 (96.9\%) of the patients achieved FMF-50 scores (Table 3). There was no significant difference in efficacy when comparing anakinra and canakinumab $(p>0.05)$.

The median proteinuria was $3.2 \mathrm{~g} /$ day (range, $0.5-11.2$ $\mathrm{g} /$ day) before the treatment, and decreased to $1.85 \mathrm{~g} /$ day (range, 0.1-12.2) after treatment $(p=0.140)$. Based on GFR values, there was a statistically significant change in proteinuria response. The group with GFR $\geq 60 \mathrm{ml} / \mathrm{dk} /$ $\mathrm{m}^{2}$ before the treatment had $2390 \mathrm{mg} /$ day (range, 1400$7200 \mathrm{mg} /$ day) proteinuria, which decreased to $890 \mathrm{mg} /$ day (range, $120-2750 \mathrm{mg} /$ day) $(p=0.008)$. On the other hand, the median proteinuria decreased from 4472 to $3960 \mathrm{mg} /$ day (range, 2050-12,200 mg/day) for the group with GFR $<60 \mathrm{ml} / \mathrm{min} / \mathrm{m}^{2}$. This difference was not statistically significant $(p=0.345)$. When the effect on proteinuria was investigated, the other factors (diets, the using of angiotensin-receptors inhibitors or blockers and blood pressure control etc.) of all patients were similar in both groups.

\section{Side effects}

Allergic reactions were observed in eight (19.5\%) patients who used anakinra, and severe neutropenia was observed in one patient (2.4\%). Another patient (2.4\%) was diagnosed with Multiple Sclerosis after 2 years of anakinra use. In the group that used anakinra, one (2.4\%) patient who also had polyarteritis nodosa (PAN) and sacroiliitis died due to sepsis. Mild infections of the upper respiratory tract and urinary tract were reported by $7-30 \%$ of the patients. There was no significant difference in the rate of side effects when comparing anakinra and canakinumab $(p>0.05)$. Although the glomerular filtration rate (GFR) increased during the treatment period, this difference was not statistically significant (Table 2).

\section{Pregnancy and other conditions}

We found that two patients continued to use anakinra during their pregnancy, and there were no problems during pregnancy, birth, or with the child.

We switched to another biological medicine for five (7.6\%) patients (four canakinumab, one anakinra). Two out of five patients had stage-three sacroiliitis. Even though the FMF attack frequency decreased for these patients, we switched to tumor necrosis factor (TNF) inhibitor treatments due to their high Bath Ankylosing Spondylitis Disease Activity Index (BASDAI) scores. Although one $(2.4 \%)$ patient used anakinra $(100 \mathrm{mg} /$ day $)$ regularly for 3 months, knee arthritis continued at a rate of twice per month. For this patient, we switched to tocilizumab, and knee arthritis responded to this treatment. We considered the wash-out period of anakinra and canakinumab when we started patients on tocilizumab. Complete remission was achieved for about 14 months in a patient who used canakinumab due to both peritonitis and peripheral arthritis attacks. However, the treatment was changed to tocilizumab because the number of attacks was once or more per month. One of the patients $(2.4 \%)$ had end-stage kidney failure and had renal transplant due to inadequate response to the treatment (Table 4).

The median duration of anti-IL-1 treatment $(n=6$ (85\%) for anakinra; $n=1$ (15\%) for canakinumab) was 3 months (range, 3-26 months) for the seven (10.8\%) 
Table 2 Comparison of laboratory values and disease severity before and after Anti-IL-1 therapy

\begin{tabular}{llll}
\hline & Before treatment & After treatment & 0 \\
\hline Attack frequency (per 3 months) & $3(1-6)$ & $0(0-1)$ & $.00^{*}$ \\
Patients-VAS $(0-10 \mathrm{~cm})$ & $10(9-10)$ & $2(0-3)$ & $.00^{*}$ \\
Physicians-VAS $(0-10 \mathrm{~cm})$ & $9(8-10)$ & $1(0-2)$ & $.00^{*}$ \\
ESR $(\mathrm{mm} / \mathrm{h})$ & $33(9-85)$ & $29(2-106)$ & $.00^{*}$ \\
CRP $(\mathrm{mg} / \mathrm{dl})$ & $16(1-80)$ & $2(1-12)$ & $.00^{*}$ \\
GFR $\left(\mathrm{ml} / \mathrm{min} / \mathrm{m}^{2}\right)$ & $54(13-180)$ & $42(10-174)$ & .592 \\
Durations of attacks (hours) & $48(36-96)$ & $18-24)$ & $0.0^{*}$ \\
Proteinuria $(\mathrm{mg} / \mathrm{day})$ & $3200(0.5-11.2)$ & $890(120-2.75)$ & 0.140 \\
$\quad$ GFR $\geq 60 \mathrm{ml} / \mathrm{min} / \mathrm{m}^{2}$ & $2390(1400-7200)$ & $3960(2050-12.2)$ & $0.008^{*}$ \\
GFR $<60 \mathrm{ml} / \mathrm{min} / \mathrm{m}^{2}$ & $4472(1950-11.2)$ & 0.345 \\
\hline
\end{tabular}

Values presented as median (minimum-maximum).VAS Visual Analogue Scale $(0-10 \mathrm{~cm}), C R P$ C reactive protein, GFR glomerul filtration rate, ESR Erythrocyte Sedimentation Rate *: $p<0.05$

patients with renal transplantation. No side effects or drug-interactions were observed.

\section{Discussion}

In this study, we present the results of 65 FMF patients treated with anti-IL-1 agents. We show that IL-1 inhibitors are effective and safe in patients with FMF who are colchicine resistant/intolerant or with amyloidosis. Approximately $5-10 \%$ colchicine resistance and $5-10 \%$ colchicine intolerance have been reported during FMF treatment [8]. The use of anti-IL-1 treatments has increased among patients with colchicine-resistance. Some previous studies have demonstrated the efficiency of these treatments. Akar et al. reported the response rate as $76.5 \%$ in the anakinra group and $67.5 \%$ in the canakinumab group in a total of 172 colchicine-resistant patients [9]. In the study by Kucuksahin et al., anti-IL-1 treatments significantly decreased the number of attacks in 26 colchicine-resistant patients with FMF. Moreover, the serum acute phase reactants of these patients returned to normal levels [10]. Kohler et al. achieved a 90\% FMF-50 score with IL-1blocking therapy in 31 FMF patients [11]. In our study, we achieved a 96\% FMF-50 response rates for the anti-IL-1 treatments, which is similar to previous studies. Currently, the prevention

Table 3 FMF-50 response criteria

\begin{tabular}{ll}
\hline Parameters & At least 50\% reduction \\
\hline Attack frequency & $63 / 65(96.9 \%)$ \\
Durations of attacks & $63 / 65(96.9 \%)$ \\
Patients VAS & $64 / 65(98.5 \%)$ \\
Physicians VAS & $64 / 65(98.5 \%)$ \\
CRP (at least 2 weeks after the last attack) & $62 / 65(95.3 \%)$ \\
Arthritis & $9 / 11(81.8 \%)$
\end{tabular}

Values presented by \% frequency. VAS Visual Analogue Scale, CRP C reactive protein and decreasing effects of anakinra and canakinumab were recognized in FMF attacks.

However, additional amyloidosis and spondyloarthritis (SpA) diagnoses can lead to some issues in FMF treatment. Some studies have reported a decreasing effect of anti-IL-1 treatment in proteinuria. By biopsy, Topaloglu et al. reported that anti-IL-1 treatments reduced proteinuria but also resulted in renal damage in three patients with AID-associated amyloidosis [12]. Özçakar et al. reported a significant decrease in the amount of proteinuria and an increase in quality of life in six children with FMF-associated amyloidosis [13]. Another Varan et al. showed that anti-IL1 treatments significantly reduced the amount of proteinuria (from $1606 \mathrm{mg}$ /day to 519 $\mathrm{mg} /$ day) [14]. Moreover, national data that was collected with 172 subjects demonstrated a significant decrease in proteinuria $(5458.7 \mathrm{mg} / 24 \mathrm{~h}$ before and $3557.3 \mathrm{mg} / 24 \mathrm{~h}$ after) [9]. Instead, in these studies, patients were not sub-grouped, and their data was not analyzed regarding their GFR. In our study, anti-IL-1 agents significantly decreased the proteinuria in patients with GFR $>60 \mathrm{ml} /$ $\mathrm{min} / \mathrm{m}^{2}$, while no significant reduction was seen in patients with GFR $<60 \mathrm{ml} / \mathrm{min} / \mathrm{m}^{2}$. Therefore, we emphasized that GFR would be a useful indicator to decide the proper treatment for these patients. Another option is tocilizumab, which is an IL-6 blocking agent that has been recently started to be used in the treatment of FMF-associated amyloidosis. Ugurlu et al. [15] reported a reduction effect of tocilizumab on proteinuria among 20 subjects. Additionally, in this study, only two patients had $\mathrm{GFR}<50 \mathrm{ml} / \mathrm{min} / \mathrm{m}^{2}$; these patients were offered tocilizumab treatment and responded positively. Despite these positive outcomes, the small sample size of these studies and the lack of a randomized controlled trial (RCT) creates confusion around this topic. Also factors such as blood pressure control, use of angiotensin receptor blocker drugs or colchicine and diet have positive 


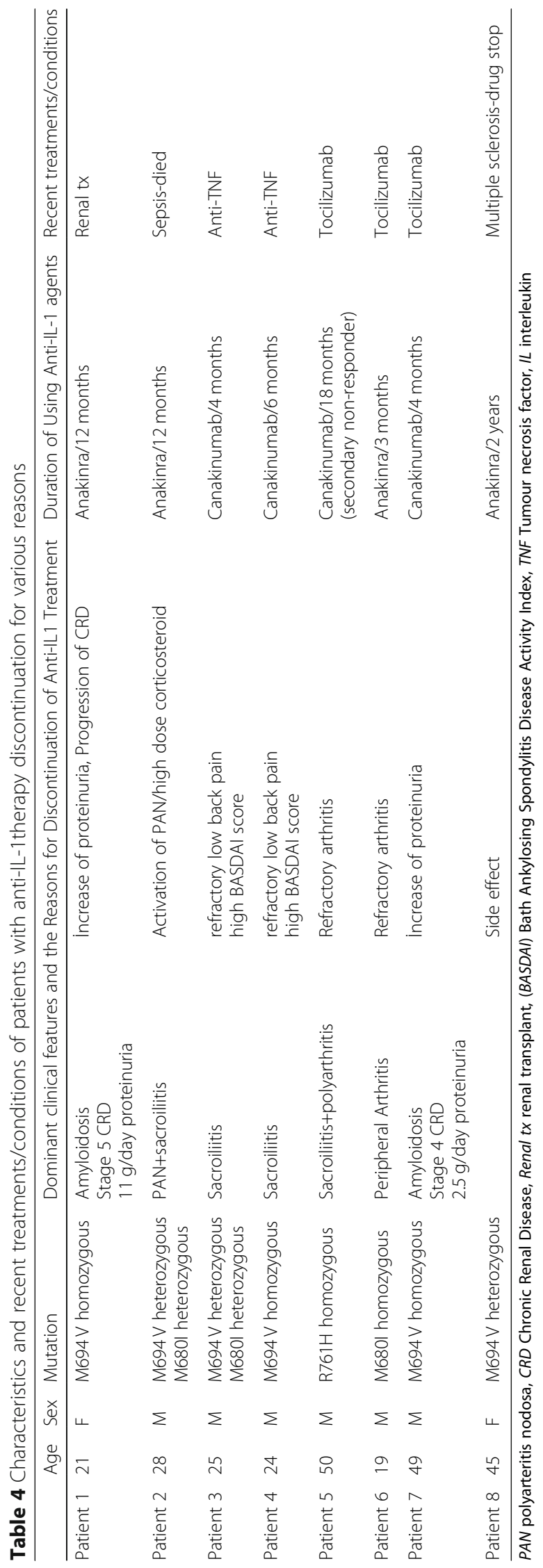


effects in decreasing proteinuria. However, it is not easy to evaluate them clearly.

There are many studies on anti-TNF agents in patients with colchicine resistant FMF or FMF associated with sacroiliitis or peripheral arthritis. However, none of these studies were RCTs. In one review, Koga et al. reported that 29 FMF patients in various studies had successful results with anti-TNF agents [16]. The efficacy of antiTNF drugs in the treatment of colchicine-resistant FMF is not yet clear. EULAR recommends using anti-TNF therapy, especially in cases with FMF-associated SpA and peripheral arthritis [7]. Interestingly, according to a recently published study, the $M 694 \mathrm{~V}$ gene variations were seen five-times as often among Ankylosing Spondylitis (AS) patients compared to a healthy population, and this variant might be associated with AS. In the same study, the serum level of IL-1 was higher in AS patients. Therefore, the researchers emphasized that antiIL-1 treatments would be an appropriate therapy in these patients [17]. However, in our study, ten patients had axialspondyloarthritis (AxSpA), and only half of these subjects had proper anti-IL-1 treatment. The treatments in other patients had to be replaced with other biological treatments, such as anti-TNF. Only one patient was excluded from the study. The efficacy of antiIL-1 treatments on AS patients should be investigated through RCTs.

In terms of safety issues the number of patients and the duration of drug use can be considered as a limitation. During the study, we did not detect any serious infection or tuberculosis or malignancy. While allergic reactions are commonly seen as an adverse effect of anakinra, in a review of 27 studies published by van der Hilst et al., it was shown that there were no serious infections when using IL-1 blocking agents. In addition, allergic reactions had been reported in just $6.5 \%$ of patients [18]. In our study, $19.5 \%$ of allergic reactions were detected in patients using anakinra. In this study, a participant who was using additional steroid and immunosuppressive agents had sepsis and died. Therefore, identification of anakinra as the main factor responsible for this death is impossible. While seven renal transplant patients were offered anakinra and the other immunosuppressive, no severe infections or drug interactions were seen. The previous studies that were carried out with renal transplant patients showed no severe adverse effect or drug interactions [19]. Multiple sclerosis is a possible adverse effect of any biological medication, and it was observed in one patient in this study. The medication was discontinued, and the patient has been followed closely. To our knowledge, there are no data available in the literature about this scenario.

Anakinra is classified as Food and Drug Administration (FDA) Pregnancy Category B. Recently, multicenter pregnancy data and case reports of pregnant women who have been using anti-IL-1 have been published. Among thirty-one pregnant women who were using canakinumab or anakinra (eight and 23 respectively), only one patient experienced renal agenesis [20,21]. In our study, two pregnant patients safely used anakinra treatment throughout their pregnancy, and no fatal or maternal complications were noted.

Also, to identify new mutations and epigenetic mechanisms, whole gene analysis should be done in refractory FMF patients.

The main limitation of our study is that it is an observational study. The efficacy of anti-IL-1 treatment should be shown with randomized controlled trials. Another limitation is that these off-labeled medications were offered as fixed doses. Long term follow-ups are crucial to identify the long-term and potential adverse effects of this medication. The serum level of amyloid A has not been measured in all participants; therefore, there was no evaluation of it.

\section{Conclusion}

As a conclusion, anti-IL treatments among colchicineresistant patients with FMF continue to be used as an effective treatment. However, this treatment is less effective against proteinuria in patients with stage 4 or 5 kidney disease. In our study, anti-TNF and tocilizumab have provided more successful outcomes in participants with FMF associated arthritis and sacroiliitis. RCTs should be conducted to demonstrate the efficiency of the treatment in these clinical situations. Further studies are needed to determine the safety and long-term side effects of anti-IL-1 therapies.

\section{Acknowledgements \\ Not applicable.}

Authors' contributions

All authors have contributed equally to the development of the manuscript. All authors read and approved the final manuscript.

\section{Funding}

The authors have no relationships with the pharma agencies promoting the drugs presented in the manuscript, and received no funding of this study.

\section{Availability of data and materials}

The authors confirm that the data supporting the findings of this study are available within the article.

\section{Ethics approval and consent to participate}

The approval from the ethics committee of Cumhuriyet University Medical Faculty was obtained for this study with the decision no 2019-04/29. The study was carried out in accordance with the World Medical Association's Declaration of Helsinki. Patients' informed consents were obtained.

Consent for publication

All authors consent to publish the manuscript in Advances in Rheumatology.

Competing interests

The authors declare that they have no competing interests. 


\section{Author details}

'Department of Internal Medicine - Rheumatology, Faculty of Medicine, Cumhuriyet University, Unit Sivas Cumhuriyet, 58140 Sivas, Turkey. ${ }^{2}$ Department of Biostatistic, Medical Faculty, Sivas Cumhuriyet University, Sivas, Turkey.

Received: 6 October 2019 Accepted: 22 January 2020

Published online: 30 January 2020

\section{References}

1. Ozdogan H, Ugurlu S. Familial Mediterranean fever. Presse Med. 2019;48(1): e61-76. https://doi.org/10.1016/j.lpm.2018.08.014

2. Onen F, Sumer H, Turkay S, Akyurek O, Tunca M, Ozdogan H. Increased frequency of familial Mediterranean fever in Central Anatolia, Turkey. Clin Exp Rheumatol. 2004;22(4 Suppl 34):S31-3.

3. Sari I, Birlik M, Kasifoglu T. Familial Mediterranean fever: an updated review. Eur J Rheumatol. 2014;1 (1):21-33. https://doi.org/10.5152/eurjrheum.2014.006.

4. Tunca M, Akar S, Onen F, Ozdogan H, Kasapcopur O, Yalcinkaya F, et al. Familial Mediterranean fever (FMF) in Turkey: results of a nationwide multicenter study. Medicine (Baltimore). 2005:84:1-11.

5. Sethi S, Theis JD. Pathology and diagnosis of renal non-AL amyloidosis. J Nephrol. 2018;31(3):343-50. https://doi.org/10.1007/s40620-017-0426-6.

6. Gül A. Approach to the patients with inadequate response to colchicine in familial Mediterranean fever. Best Pract Res Clin Rheumatol. 2016;30(2):296303. https://doi.org/10.1016/j.berh.2016.09.001.

7. Ozen S, Demirkaya E, Erer B, Livneh A, Ben-Chetrit E, Giancane G, et al. EULAR recommendations for the management of familial Mediterranean fever. Ann Rheum Dis. 2016;75(4):644-51. https://doi.org/10.1136/ annrheumdis-2015-208690.

8. Hentgen V, Grateau G, Kone-Paut I, Livneh A, Padeh S, Rozenbaum M, et al. Evidence-based recommendations for the practical management of familial Mediterranean fever. Semin Arthritis Rheum. 2013;43:387-91.

9. Akar S, Cetin P, Kalyoncu U, Karadag O, Sari I, CInar M, et al. Nationwide experience with off-label use of Interleukin-1 targeting treatment in familial Mediterranean fever patients. Arthritis Care Res. 2018;70(7):1090-4. https:// doi.org/10.1002/acr.23446.

10. Kucuksahin O, Yildizgoren MT, Ilgen U, Ates A, Kinikli G, Turgay M, et al. Anti-interleukin-1 treatment in 26 patients with refractory familial mediterranean fever. Mod Rheumatol. 2017;27(2):350-5. https://doi.org/10. 1080/14397595.2016.1194510.

11. Kohler BM, Lorenz H-M, Blank N. IL 1-blocking therapy in colchicine-resistant familial Mediterranean fever. Eur J Rheumatol. 2018;5(4):230-4. https://doi. org/10.5152/eurjrheum.2018.18036.

12. Topaloglu R, Batu ED, Orhan D, Ozen S, Besbas N. Anti-interleukin 1 treatment in secondary amyloidosis associated with autoinflammatory diseases. Pediatr Nephrol. 2016;31(4):633-40.

13. Özçakar ZB, Özdel S, Yılmaz S, Kurt-Şükür ED, Ekim M, Yalçınkaya F. Anti-lL-1 treatment in familial Mediterranean fever and related amyloidosis. Clin Rheumatol. 2016;35(2):441-6.

14. Varan Ö., Kucuk H., Babaoglu H., Guven SC., Ozturk MA., Haznedaroglu, et al (2019). Efficacy and safety of interleukin-1 inhibitors in familial Mediterranean fever patients complicated with amyloidosis. Mod Rheumatol, 29(2), 363-366. https://doi.org/10.1080/14397595.2018.1457469.

15. Ugurlu S, Hacioglu A, Adibnia Y, Hamuryudan V, Ozdogan H. Tocilizumab in the treatment of twelve cases with aa amyloidosis secondary to familial mediterranean fever. Orphanet J Rare Dis. 2017;12(1):105. https://doi.org/10. 1186/s13023-017-0642-0.

16. Koga T, Migita K, Kawakami A. Biologic therapy in familial Mediterranean fever. Mod Rheumatol. 2016;26(5):637-41.

17. Li Z, Akar S, Yarkan H, Lee SK, Çetin P, Can G, et al. Genome-wide association study in Turkish and Iranian populations identify rare familial Mediterranean fever gene (MEFV) polymorphisms associated with ankylosing spondylitis. PLoS Genet. 2019;15(4):e1008038. https://doi.org/10. 1371/journal.pgen.1008038

18. van der Hilst JC, Moutschen M, Messiaen PE, Lauwerys BR, Vanderschueren S. Efficacy of anti-IL-1 treatment in familial Mediterranean fever: a systematic review of the literature. Biologics. 2016;10:75-80.

19. Trabulus S, Korkmaz M, Kaya E, Seyahi N. Canakinumab treatment in kidney transplant recipients with AA amyloidosis due to familial Mediterranean fever. Clin Transpl. 2018;32(8):e13345. https://doi.org/10.1111/ctr.13345.
20. Youngstein T, Hoffmann P, Gül A, Lane T, Williams R, Rowczenio DM, et al. International multi-Centre study of pregnancy outcomes with interleukin-1 inhibitors. Rheumatology (Oxford, England). 2017;56(12):2102-8. https://doi. org/10.1093/rheumatology/kex305.

21. Illgen $U$, Küçükşahin $O$. Anakinra use during pregnancy: report of a case with familial Mediterranean fever and infertility. Eur J Rheumatol. 2017:4(1):66-7.

\section{Publisher's Note}

Springer Nature remains neutral with regard to jurisdictional claims in published maps and institutional affiliations.

\section{Ready to submit your research? Choose BMC and benefit from:}

- fast, convenient online submission

- thorough peer review by experienced researchers in your field

- rapid publication on acceptance

- support for research data, including large and complex data types

- gold Open Access which fosters wider collaboration and increased citations

- maximum visibility for your research: over $100 \mathrm{M}$ website views per year

At BMC, research is always in progress.

Learn more biomedcentral.com/submissions 